\title{
Theoretical Foundations of "Competitive Team-Based Learning"
}

\author{
Seyed Mohammad Hassan Hosseini, PhD (TESOL) \\ Imam Ali (A) High School, Gaz Sharghi, Mashhad, Iran \\ E-mail: mhhosseini2002@gmail.com
}

\begin{abstract}
This paper serves as a platform to precisely substantiate the success of "Competitive Team-Based Learning" (CTBL) as an effective and rational educational approach. To that end, it brings to the fore part of the (didactic) theories and hypotheses which in one way or another delineate and confirm the mechanisms under which successful (language) learning occurs and then tries to correlate such mechanisms to those inherent in CTBL settings. This, bridging the gap between theory and practice, would, $i$ hope, enable educators to better recognize the nature and the major goals of my instructional approach and consequently its pivotal significance especially for the present context of globalization not only as a sophisticated, modern, super-flexible, inclusive, and relevant and realistic approach to ELT/Education, but as a 'weapon' as well. My "Theory of Language" and also my "Multiple Input-Output Hypothesis", which are the axes of my approach, have also been thrown into sharp relief in this paper. The present conceptual paper, as such, is bound to benefit (ELT) teachers in terms of its contribution to their knowledge building, and critical, analytical, and creative thinking, and thus further pedagogical achievement and professional development.
\end{abstract}

Keywords: Critical attitude of mind, Oppression, Method engineering, Catalyst for transformation, Elimination of apartheid/dictatorship

\section{Introduction}

I transformed my philosophy into my instructional approach, Competitive Team-Based Learning (CTBL), availing myself of the present methods especially in the arena of CL methods, in 1994 to more comprehensively and systematically target the roots to our socio-educational/cultural/economical/political problems, occasioned by the conventional antediluvian education systems, in the present world context (see Hosseini, 2000/2007/2010). CTBL is a holistic contextualized approach to teaching and learning that reflects the real world holism. Particularly, it foregrounds the significance of effective teamwork amidst competitive environments not only to foster academic progress of students but also to more effectively contribute to their future success, both academically and socially.

\section{Theory of language}

There is no doubt, today, in the idea that language is a social phenomenon. Language is a tool for social relations and performance of social transactions among individuals. In its theory of language, therefore, CTBL, postulates language use and language learning as interactive activities which occur best in contexts where encourage discussion and negotiation of meaning, and learner active participation in group activities that involve risk taking, hypothesis testing, plan/decision making, problem solving, and making judgments about the achieved progress (i.e., developmental evaluation). In words of one syllable, CTBL espouses the 'interactional' view of language, the developed combination of structural and functional views of language, and so prioritises both the knowledge of 'appropriate use of meaningful language' and the ability to 'manage discourse interactions', to use Richards and Rodgers' (2001) terms.

Furthermore, i am also firmly of the stand that language, which develops best in social interaction, is a means for thinking. This claim could be justified by the fact that one may not be able to think without (mental) use of language. Simply put, language facilitates managing/engineering mental activities/thinking. Keeping this in mind, the point, in my view, is that thinking is crucial not just for (language) learning to take place and for successful social interaction, it is also the very requirement, if not the key, for any form of reform, change, and transformation, which have been the main motive for me to develop my instructional weapon. Thinking, thereby, i reckon, is the most powerful as well as complex psychological tool or artefact for building organised and just societies, which better contribute to world peace - the ultimate dream of humanity in today world context. This theory of mine and its affiliated approach to different forms of transformation per se could justify the reason as to why the mechanism underlying CTBL focuses upon improving different aspects as well as quality of thinking (particularly higher order analytical thinking) abilities of students with especial attention to the significance of process of thinking in reasoning growth. It is based on such premises that CTBL provides students more opportunities to obtain knowledge, comprehend it, understand it, apply it, analyze it, synthesize it, and evaluate it 
and make judgments 'via the application of language' to genuine shared learning environments, with the scaffold of their peers. (See also the section on Multiple Input-Output Hypothesis). For example, in CTBL bona fide environments, students have significantly more opportunities not only to listen to their more capable partners, in their teams, while they are thinking aloud (i.e., while they are explaining a point/problem or a solution to a problem to them, by using language), which allows them to acquire their approaches to thinking and their thinking skills, but also to use language - to think - in such contexts. Moreover, CTBL provides students the significant opportunities to produce/use language in more complicated contexts such as in class-wide discussions or in team tournaments wherein they are also challenged to support their answers/ideas with reason and logic (i.e., to practice purposeful thinking - by using language, in the course of interaction with others). To put it another way, one outstanding feature of my instructional approach refers to the fact that it draws on 'language' as a tool for empowering individuals' minds with critical approaches to analytical and divergent thinking skills in order to enable them to transform the world and in so doing to transform the conditions of not only their own existence but also the humanity.

As it is realised, from the point of view of my theory, language, as a social phenomenon, and as the most complicated logic of history, is the cornerstone of human prosperity. That is, language develops best in interaction of individual with others, and, in its turn, contributes to their thinking/reasoning abilities, and an individual with a powerful mind, who is naturally rational, would have a more successful social relationship and would more effectively contribute to just societies and world peace. Therefore, in my view, social interaction, language development, reasoning abilities, learning, and social development and world peace are inextricably interwoven.

\section{View of learning}

In CTBL, i have tried to focus on process and condition of learning alike. This is why group activities with a focus on higher order analytical thinking skills such as analysis of causes and effects, synthesising, and evaluating, inferring, and making judgements which are supported by appropriate, engaging, and relaxing environments are encouraged in this approach. Language learning is considered as a unified, personal, and social experience that best happens in a web of relationships. As it will be elaborated in the following sections, a wide variety of theoretical perspectives come to substantiate the idea. As noted, almost all of them prioritize the importance of social interaction, the focused area of CTBL, in (language) learning.

\subsection{Constructivists' theories}

Constructivism has come to emphasize the significant role of social interaction in learning at the dawn of the 21 st century though its origin, as Candy (1991) corroborated, dates back to the pre-Socratic Parmenides in the 5th century B.C. According to constructivists, language learning is a kind of problem solving activity which requires complex intellectual processes, and occurs more effectively in situations where learners have the opportunities for mutual interaction and negotiation. The belief is that such learning together contexts bring with them rich and necessary opportunities for language learning. For example, opportunities for participants not only to explain and to receive explanations but also to reflect on reactions and perspectives of their counterparts arise. Also, in such situations, with the scaffold of their peers, learners can more effectively relate course materials into their obtainable schema or conceptual frameworks. These conditions are believed to be conducive to a deeper level of understanding of the language which, in its turn, results in cognitive growth.

However, as Duffy and Cunningham (1996) put it, constructivism has two main schools of thought: While on the one hand, some of its philosophers like Dewey, as a cognitive constructivist, and Piaget, as a socio-cognitive constructivist, have focused upon 'individual' in the group; on the other hand, social constructivists, like Vygotsky, have placed the accent on the socially and culturally situated context of cognition in which knowledge is constructed as shared endeavours.

\subsubsection{Cognitive theories}

John Dewey whose ideas brought a profound revolution in Education was one of the most prominent educators of the early 20th century. This American philosopher's pragmatic approach to educational thinking via his concern for interaction, reflection, and experience, and his interest in community and democracy contributed to the development of informal education, education that must engage with and enlarge with experience. He implied the idea that students should be trained not to accept new ideas and ideologies without critical processing and reasoning.

Dewey believed that, instead of being passive, students must actively get involved in learning, which he considers as a complicated process. Students, in his view, should be engaged in whatever enhances their learning. 
They should interact with one another so as to receive feedback on their activities and learn and acquire some societal interpersonal skills needed for maintaining better social cohesion. Dewey (1938) articulated the differences of his 'progressive' approach with traditional education as under:

If one attempts to formulate the philosophy of education implicit in the practices of the new education, we may, this researcher thinks, discover certain common principles... To imposition from above is opposed expression and cultivation of individuality; to external discipline is opposed free activity; to learning from texts and teachers, [is opposed] learning from experience; to acquisition of isolated skills and techniques by drill is opposed acquisition of them as means of attaining ends which make direct vital appeal of the opportunities of present life; to static aims and materials is opposed acquaintance with a changing world. (pp. 19-20)

As a neo-Deweyian educator and of course as a neo- Freireian in outlook and a neo-Hosseinian (Imam Hossein Shia's $3^{\text {rd }}$ holy Imam) in temperament, i have tried to focus upon developing 'intellectual power' and 'reflective thought' of my students in CTBL well-designed meaningful contexts. CTBL provides students the opportunities to develop and internalise a broad outlook and the ability to generate different strategies for facing the emerging issues, ideas, ideologies, and so forth in the real world settings. For instance, in confronting a posed-by-me idea, issue, or even ideology, students are practised to 'critically' become aware of it, challenge it, experience it, feel and touch it, and penetrate deep into it through different dimensions within an 'ask, don't tell' atmosphere in order to understand it better and enable themselves to accept, modify, or reject it. Real, genuine, intuitive, and searching questions that engage and persuade exploration are emphasised simply because i believe real mind empowerment stems - to a high extent - from developing such questions. As an integrative rather than autocratic leader, i try to contribute to the critical awareness of my students' minds, and train them in such a way not to accept not merely new ideas and ideologies, but even the norms and principles of the society and even me, their leader, without critical processing, reasoning, and reflection. Needless to say, critical thinking per se is of great help to students' intellectual growth and language development. Below can be considered as some guidelines, which refer to developing critical attitude of my students and their strategies for coping with emerging problems/ideologies, and so on in their daily lives:

The bitter truth and of course the root to our miseries refers to the fact that most of you live through a paradigm that others define or prescribe for you. This is why you are seeing 'every thing' (e.g., ideas, problems, solutions, ethics, etc.) through their eyes. This is not appropriate especially for today world citizenry. To see and interpret things 'as they are', you must be able to transform your awareness beyond the mind - this is the key to your future prosperity! To that end (transforming your awareness), you need to be able to hinder others' thoughts, perspectives, and beliefs cloud your awareness, but you should also be able not to let your own feelings and thoughts cloud the consciousness beyond your mind. I mean to say you should be capable enough to tear off the screen of illusion and then try to see things through the critical attitude of your beautiful as well as potentially powerful mind. In confronting a problem or even a person, for instance, you should, first and foremost, be able to decolonise your mind, and then try to critically become aware of it and try to discover its nature and essence through activities like abstract thinking and reasoning in order to define it, analyze it, and generate hypotheses. Importantly, in the process, you should likewise try out a response and experience the consequences in order to deepen your understanding of it. As such, you put yourself in a safe position to confirm, modify or reject your previous knowledge or interpretations for developing an effective idea to solve/cope with/address it. Developing such habits of mind, will, i am sure for certain, in the long haul though, capacitate you to transform the world.

And the below guidelines refer to academic skills that i provide in CTBL situations, in a reading course for example, when i feel my students need to be aware of such strategies:

.... Deductive thinking is a significant strategy which you should internalise. Deductive thinking necessitates the ability to see things/happenings from the above, while not ignoring the details. To cite an example, there are many situations that you will not be able to understand a text/book unless you are familiar enough with its creator - with the writer. Sometimes, you should penetrate even further: You should go for the context/circumstances within which the writer has developed its text/book. I mean to say, a word, text, book, or event out of context is like a fish out of water. Therefore, you must take great care in trying to understand even what the author is trying/intending to get you at, by thinking critically about the author, the circumstances in which s/he has created its manuscript, and the arguments and the facts which support it. For example, you cannot understand the book titled 'Animal Farm' if you do not know especially the political context in which this magnificent masterpiece has been developed. The next step that you, as readers, should take is to look for the features in the text/book that scaffold it. These features include its title, sub-headings, topic sentences, and graphs, if any, all of which assist you predict the content, the theme, and the writer's purpose. ...In course of the endeavour for understanding the text/book and constructing appropriate interpretations of it, you need not to 
know every word. Skipping unknown words but resorting to other strategies like applying background knowledge, which has been proved to, sometimes, significantly contribute to more effective learning, would be helpful. A deductive approach to thinking thereby produces far more realistic conclusions.... What is of crucial importance to me is that you should not accept (the writer's) ideas/ideology/school of thought without critical processing, reasoning, and reflection. For that reason, i strongly recommend you that in addition to underlining the key points and paraphrasing the main ideas in the course of reading a typescript, take notes of your uncertainties and doubts and raise genuine to-the-point critical questions for the discussion time.

Competitive Team-Based Learning, thereby, intends to train students to act as critical as well as creative knowledge seekers instead of reticent bench-bound sheep-like vacuumed objects. In sum, the significance of such mini democratic contexts, in my Islamic-oriented democratic (is)lands - my classes, is thus that they provide opportunities for my people to acquaint with human relationship principles and values, and internalize humanitarian ways of interaction, thinking, reasoning, and living.

\subsubsection{Socio-cognitive theories}

Most of socio-cognitive theories are based on the work of Jean Piaget, the prominent Swiss biologist. According to Piaget (1973), experience and societal environmental factors are favourable to the development of intelligence in individuals which is one of the main goals of Education. Specifically, he has prioritised the significant contribution of 'cognitive conflict' (i.e., when there is no match between the background knowledge and the new information), in the process of social interaction, to the development of cognition. As he contended in his Socio-Cognitive Conflict Theory, discussions and disagreements of individuals with diverse perspectives in the course of their interactions, in their milieu, naturally result to cognitive dissonance, and this, along with the immediate feedback they receive in such situations, motivates them to investigate the incongruities between their understandings. And this kind of circumstances spurs discussants to 'reconsider their ideas'. The significance of this activity is that it demands reassessment, reshaping or modification, and even changing of ideas. Hence, interaction of peers in learning settings, as Piaget offered, effects real exchange of reasoning, which encourages meta-cognition and facilitates the development of schemata or the intellectual structures. This development, as Piaget and Inhelder (1969) reasoned, is possible through 'assimilation', fitting a new experience into an existing mental structure (schema); the process of 'accommodation', revising an existing schema because of a new experience, and 'adaptation' or 'equilibrium', as the result of assimilation and accommodation, which brings increased adjustments in the environment.

Competitive Team-Based Learning overlaps with socio-cognitive theories in the sense that it foregrounds the crucial importance of especially Piagetian cognitive disequilibrium, as a "vehicle for transformation and change'-- change in cognition, reasoning styles and approaches, attitudes, ideas, and even the world. As an agent of change, i, in my CTBL classes, try to problemitize the learning context and then encourage my students to discuss problem solving activities, in an ambience of heterogeneous teams in competitive environments, so that they listen to diversity of ideas, develop their cognition, cognitive reasoning, and critical attitude of their minds or their critical thinking abilities, and in the process, cultivate objectivity of mind. 'Leading', to more effective learning and development, 'by questioning' is my favourite activity in such circumstances. I am on a constant lookout for appropriate opportunities to further problemitize such contexts via posing my questions (or ideas). Genuine, captivating, powerful, and thought-provoking questions that tap into and activate my students' innate skills and abilities are focused upon. I am particularly interested in employing such type of queries that have the capacity to push the edges of my students' thinking and motivate a pursuit for resolution via fostering especially 'outside-the-box' thinking. Such questions naturally contribute to cognitive dissonance and so activate the critical attitude of my students' minds, reinforce meta-cognition, and encourage risk taking in thinking (creative thinking), all of which are favourable to more effective and real (language) learning. But the point is that merely enabling my students to answer my strategic questions never satisfies me. I thereby try to train them in such a way that it ensures their power to develop pertinent and challenging critical questions as well (recall that my students are expected to influence the world). In sum, such situations, in my view, not only provide an effective context for the development of new understandings (e.g., by contributing to genuine cognitive dissonance and stimulating authentic discussions), but they also give my students a voice and broadcast respect for opinions and expertise, and communicate value. They thus lend themselves well to various settings like creative problem solving, team building, more effective participation and teamwork, a successful learning ethos and direction-setting, and valuable learning and, of course, reasoning and personal growth.

\subsubsection{Cognitive socio-cultural theories}

Current conceptualizations of Socio-Cultural Theory draw heavily on the work of Russian psychologist and 
linguist Lev Semenovich Vygotsky and some other theoreticians like J. V. Wertsch. Vygotsky, in his Socio-Cultural Theory, deemed learners as culturally and historically situated rather than isolated individuals. Accordingly, he focused his attention on the significant contribution of social context to individuals' effective learning. To highlight the key role of social interaction for learners' development, Vygotsky (1981), for his part, made the argument as follows:

Any function in the child's cultural development appears twice, or on two planes. First it appears on the social plane, and then on the psychological plane. First it appears between people as an interpsychological category, and then within the child as an intrapsychological category. This is equally true with regard to voluntary attention, logical memory, the formation of concepts, and the development of volition.... it goes without saying that internalisation transforms the process itself and changes its structure and functions. Social relations or relations among people genetically underlie all higher functions and their relationships. (p. 163)

Vygotsky's Zone of Proximal Development (ZPD) Theory well manifests his philosophy. According to this theory, higher order developments such as cognitive and language development are facilitated through social interaction as it provides the ideal matrix for shared reasoning, learning, and knowledge construction. Vygotsky (1978, p. 86) defined the 'Zone' of his theory as "the distance between the actual developmental level" -- the development a child can have without the help of others - and "the proximal level"-- the development a child can do in cooperation with others, in interactive environments. To put it another way, ZPD refers to the area of knowledge that learners can construct 'only' with the scaffold of their peers via mutual interaction. This theory puts into concise that the knowledge individuals gain in such circumstances far exceeds the one they could do otherwise. This theory also reminds me of the relevance of ideas like $1+2>3$, and $\mathrm{H} 2+\mathrm{O}>\mathrm{H} 2$ and $\mathrm{O}$, which imply the idea that the solution, idea, and so on coming from two minds is never comparable to the one coming from one.

Vygotsky's exhilarating ideas have received a good deal of attention of language educators (see e.g., Dunn \& Lantolf, 1998; Kowal \& Swain, 1994; Swain \& Lapkin, 1995). This is by virtue of their great emphasis on the significant role of scaffolding or meditated learning, in appropriate interactive environments, and the kind of dialogue it brings with it for the acquisition of language. In an attempt to more directly correlate Vygotsky's theory to EFL/ESL settings, Ohta (2001) redefined the ZPD as "the distance between actual developmental level as determined by individual linguistic production, and the level of potential development as determined through language produced collaboratively with a teacher or peer" (p. 9).

The insight which Newman and Holtzman (1993) captured effectively in the concept of Vygotsky's strategy allowed them to define the relation of his strategy to CL. They offered a nice argument in this regard:

Vygotsky's strategy was essentially a cooperative learning strategy. He created heterogeneous groups of ... children (he called them a collective), providing them not only with the opportunity but the need for cooperation and joint activity by giving them tasks that were beyond the developmental level of some, if not all, of them. Under these circumstances, children could create a ZPD for each other, something not possible if one takes developmental level as the basis for learning. (p. 77)

I am firmly inclined to the view that learning best occurs through reflective inquiry with others who help the learner negotiate his or her own ZPD or degree of potential under the best conditions. To actualize a full range of interactive activities and to build an appropriate environment that brings a sort of reciprocal aid for more effective learning, i, in my method, have tried to provide students with opportunities to scaffold one another's learning in communities of learning which accommodate 'multiple whos'. These multiple whos, as Van Lier (1996) also confirmed, is expanded to include "(a) assistance from more capable peers, (b) interaction with equal peers, (c) interaction with less capable peers, and (d) inner resources" (p. 193). In sum, CTBL focuses upon bringing appropriate conditions for rich scaffolding and appropriate reciprocal aid in order to capacitate learners to overcome the difficulty gradient gradually, and facilitate them - step by step - to proceed to a higher level of development in producing their own language, ideas, ideologies, and so forth and using them more creatively and of course independently. This is so because CTBL aims at producing competent life-long and, if obligatory, independent citizens.

\subsubsection{Differentiating Piagetian and Vygotskian views}

Although Piaget's and Vygotsky's perspectives on the importance of social interaction for learning appear to resonate with each other on the surface - at first sight, they have their own distinctive features in their deeper layers. Therefore, before proceeding with our discussion of the theoretical backgrounds of CTBL, it will be useful to spend some time throwing into sharp relief such distinguishing features. For Piaget, cognitive development or the development of schemata is the result of cognitive dissonance which occurs when individual 
is in a search for equilibration or a match between background knowledge and the new information. The point is that, this, from the point of view of Piaget, 'may' happen in interaction of the individual with challenging others in his or her milieu. But for Vygotsky, learning or cognitive development is the result of scaffolding in social interaction of the individual in a community. As it was mentioned already, Piaget has explicated that the cognitive conflict, which arises in the course of social interactions, makes the individual to reconsider his or her understanding and locate the deficiencies in his or her understanding and knowledge. This spurs him/her into seeking new information, not necessarily with the help of others, in order to enrich his or her understanding for the construction of knowledge. But Vygotsky took the stand that scaffolding brings the opportunities for the individual to actively learn from others and receive their help in mutual interactions, in order to construct new knowledge.

Jacobs, McCafferty, and DaSilva Iddings (2006) pointed out another main difference between Piaget's and Vygotsky's perspectives: From Piaget's viewpoint, 'learning cannot precede development' as he was of the opinion that learning or the development of schemata occurs through some specific biological timetables and stages. He believed that the modification of these schemata or development may be facilitated via its use by the individual in interaction with his or her surroundings in the right time. But contrary to Piaget, Vygotsky (1978, p.90) argued that 'it is learning that leads development'; that is, 'the developmental process lags behind the learning process'. In confirming his belief, Vygotsky provided an excellent example: He asserted that when, in a role play, a child takes the role of a teacher, for example, s/he "always behaves beyond his average age, above his daily behaviour; in play it is as though he were a head taller than himself" (ibid. p.102). In other words, by emphasising the idea that the relationship between learning and development is poly-correlational rather than casual, Vygotsky rebutted the notion of predetermined stages, posed by Piaget, and purported that learning is anchored in interaction - in social interaction of the individual with his or her milieu.

\subsection{Andragogy theory}

Knowles' (1970/1984) theory of Andragogy, which is in support of constructivists' theories like that of Dewey, is a radical departure from traditional methods of teaching towards more interactive and humanistic learner-centred approaches. Although this theory has originally been developed for the pedagogy of adults, as Knowles himself maintained, it can be generalized to all levels of education. Knowles believed that all learners have natural potentials for learning in non-threatening and student-centred learning environments in which they do not experience excessive intervention and control of the teacher. The American educator, Knowles, in his theory, holds the view that learners should be appreciated as whole persons. They are trustworthy and accountable, and therefore should have the latitude to take responsibility for their own learning and even be consulted for the selection of the material that they think would benefit them in the real world situations. Learners are also considered as active constructors of their own learning environment (Mitchell \& Myles, 1998). According to Andragogy Theory, teachers should inform learners of what they are supposed to learn, but they should also explain to them the rational behind what they are to learn. They should likewise consider the fact that learners need to approach learning as a problem solving activity. Importantly, teachers should provide such an ambience that students could feel the immediate value of what they learn in their courses in real world situations. In short, Knowles' model of successful andragogical learning states that adults learn best when learning

1). is based on solving problems, not merely assimilating content;

2) is negotiated with learners so that their expectations and needs are met;

3) is relevant to their immediate contexts, and

4) is experiential.

One other outstanding feature of CTBL refers to its concern for bringing such learning settings that help students feel more valued, in comparison with the context in traditional systems of teaching. Learners, in CTBL environments, have the liberty to form their teams, assign one another roles, assess their partners, negotiate the course objectives with me and even critique and evaluate me. They are provided with different challenging activities which encourage them to learn different solutions to the problems at hand, via collective thinking in meaningful and reciprocal interactions. They also have the opportunities to feel and enjoy the results of their shared learning in class-wide discussions. In words of one syllable, in CTBL, i try to push my students towards feeling "the core idea" of the Andragogy Theory, which as Brookfield (1986, p.92) put it, states that "the attainment of adulthood is concomitant on adults' coming to perceive themselves as self directing individuals".

Before elaborating the connection of my pedagogical approach to the motivational and the behavioural learning theories, which are among the major premises on which CTBL emerged, in the following two sections, $\mathrm{i}$ feel $\mathrm{i}$ should suggest you not to blame me for such an attempt. Before critiquing me, 'think' to recall that even most of 
you, if not you all, as well as your societies are - sometimes insensibly though - being guided, if not controlled, via the implementation of the principles of these theories. To substantiate this claim of mine, $i$, as an attitude re-orienter and as an agent of critical awareness and social disorder -- for bringing 'an appropriate change', should resort to a rather heavy, authentic, and of course serious question: Do you not remember that for instance one of your beloved has been killed in an 'accident' just sometime after you had refused to accept a source of condescending look, oppression, or something like that?! - Think contextually (i.e., think about the event and the evidences that are likely to support it with reference to the context within which the event happened), analytically, and critically, and in the process have an eye to the beyond. Another good leading is to compare your life condition before and after your refusal. You may also wish to think about this question with reference to other people around you. Failed?! Ok, try it later when you are in a relaxed mood - when your affective filter is low. At any rate, the important distinguishing point in the implementation of the principles of these theories in my classes refers to my outlook: I do not consider my people as animals. The 'way' of and the 'purpose' for which $\mathrm{i}$ harness such principles in my lands are also in absolute contradiction to the way and the intention of your seniors.

\subsection{Motivational theories}

With the presupposition that cooperative interaction or collaboration among students on specific tasks results in better and higher levels of understanding of concepts, most of the theories dissected in this paper prioritize the importance of working together in learning situations. The motivational theories, however, come to justify particularly the mechanisms underlying CTBL settings. Motivational theories emphasize the dramatic role of incentives like grades and rewards for boosting the effectiveness of group learning in cooperative learning settings. The predominant belief is that awarding rewards to individuals or teams based on some pre-established criteria (e.g., the level of academic achievements or social skills of learners) facilitates the achievement of the curriculum's goals. Also, staunch advocates of these theories like Slavin (2000) and i (Hosseini, 2000) are against undifferentiated group grading for teamwork as it is in Johnsons' methods ${ }^{1}$ where all team members receive the same grade regardless of differences in contributions to the total-team/class effort. In their methods, the followers of school of Hosseinian/Slavinian thought consider motivational perspectives as complementary to cognitive theories on the grounds that they aim at sustaining the individual efforts and engagement in the process of learning in group activities and furthering cooperation of team members in the course of learning.

I have appreciated the important and constructive power of extrinsic motivation in my educational approach in a systematic way and of course through different dimensions. As it was noted, CTBL makes best use of the magic role of external motivators such as grades in order to bolster the motivation of individuals for further cooperation with their team members, and simultaneously encourage competition among teams. The belief is that achievement related grading systems and rewards promote positive interdependence and especially individual accountability for appropriate team functioning, and motivate learners to exert their potential for the success of their teammates with whom they have almost a common destiny. However, the significant role of intrinsic motivation is not belittled in the motivational-based CTBL settings. In point of fact, extrinsic and achievement motivation focused upon in my method are considered as complementary to intrinsic motivation, which, i reckon, most of today student already possess. External motivation potentially contributes to the success of students, which, in turn, gives them a sense of achievement. And the feeling of achievement contributes to their internal motivation. Hence, the relation among external, achievement, and internal motivation is assumed to be a cyclical process, and thus, none of them can be underestimated or ignored in learning environments, as it is in most of the methods of CL. Furthermore, it is also my belief that collaborative learning in competitive environments has a type of intrinsically rewarding nature in itself. However, in CTBL, internal motivation of students is likewise appreciated through meta-messages or motivational messages about the importance of education and real learning, for example.

\subsection{Behavioural learning theories}

According to behavioural learning theories like those of Skinner (1968) and Bandura (1977), associating certain responses with certain consequences will lead to a change in learners' behaviours. Therefore, contrary to the unhumanitarian side of this theory which encourages punishment, the humanitarian side of this theory implies the idea that immediately rewarding of correct responses of individuals to a problem motivates them for further diligence in course of problem solving. And continuity of these stimuli and responses can bring a change in their behaviours, which is considered as learning. Advocates of such theories consider rewards as stimuli for learners to commit to solve the problems with further attentiveness.

Competitive Team-Based Learning can be supported by behavioural learning theories in view of the fact that in 
my CTBL classes i provide contexts in which learners receive immediate feedback from their partners and i. I believe that immediate peer encouragement or even negative feedbacks are constructive responses that can lead to the continuity of students' learning or re-modification of their skills, strategies, attitudes, ideas, and behaviours. However, the differentiating feature is that in CTBL such corrective feedbacks are supported by relaxing and stress-free learning environments as i consider my students as communicative beings/subjects rather than repeaters/objects. One more point which needs to be reminded is that in CTBL especial attention has been given to individual and team rewards alike, with the intention to spur participants to continue their contributions to the success of not only themselves but also their teams.

\subsection{Elaboration theory}

From the perspective of Elaboration Theory, learners learn more effectively when they try to make someone else understand their intentions by articulation of their ideas and providing explanations (Slavin, 2000). Julian (1992) well posited the theme of this theory:

We learn things in different ways. One well-known distinction is between intellectual learning and experiential learning. Both types of learning are available to us and both are important. Beyond experience and understanding, however, there is a third vital element in our learning and knowing. That is the expression of our experience and understanding, the articulation of what we think and feel. That is to say, we learn by speaking, by trying to put our thoughts together and express them so that someone else can understand them. It is this way that we bring together intellectual and experiential knowledge into a coherent, individual statement which we learn as we formulate. Through this formulation, we can also prepare to act. Through action, we learn again. [Italics added]. (p. 66)

Similarly, Staarman, Krol, and Mejiden (2005) have pointed out that when learners discuss to find a solution to a problem on a topic, they verbalize their thought and this verbalization plays a critical role in learning and achievement as it elicits elaborative cognitive process. Further, as noted, in such situations the new information is easier related to the old information already in their memories.

It is well worth a note that in spite of their differences, Elaboration Theory is in tune with Gestalt theory of psychology which holds the view that when learners are able to locate an item in an intellectual structure, which usually occurs in the process of elaboration, their chances for learning increase. To bring to light the significance of elaboration through Gestalt theory, Gartner, Kohler, and Riessman (1971) explicated:

In the cognitive area, then, the child having taught another may himself learn as a result of a number of processes. He receives the material, he has to organize, prepare, illustrate the material, to present it to his students; he may try to reshape or reformulate it so as to enable his pupils to learn it and thus himself see it in new ways; he may need to seek out the basic character of the subject, its structure, in order to teach it better, and may thereby himself understand it better. (p. 62)

Competitive Team-Based Learning situations naturally facilitate involvement of all learners in elaboration of the material especially through the implementation of challenging tasks and specific activities, and also through assigning rotating roles. CTBL learning-for-all contexts thereby provide students the opportunities to unlearn and/or relearn and deepen their understanding of the material, not just through articulation of their thoughts and tutoring but also through generating genuine questions. Furthermore, they, in such dialogic-based learning situations, have to try to clarify and elaborate their meanings and ideas by reflecting on what they articulate and ask which, in its turn, as a number of scholars like Kessler (1992) and Webb (1985) have corroborated, fosters the acquisition of language.

\subsection{Speech theory}

As Candlin and Widdowson (1987) elucidated, one interesting part of Speech Theory focuses on differentiating between the illocutionary force of (any) act in speech (i.e. the purpose of the addresser or what one expects the act to achieve) and the perlocutionary effect or the actual effect of the act (the addressee's interpretation). The fact is that there are circumstances in which the addressee cannot interpret the addressor's intention in performing any speech act accurately. Sometimes, for example, what the teacher, as the addresser, intends to convey is not clear enough for students (as addressees) to understand. As such, the addressees either may not understand the purpose of the addressor or may even get it in a different way and therefore they will not understand what they are expected to.

In CTBL, authentic understandable negotiation of ideas and meanings in mutual interaction among learners is encouraged to ensure a match between teaching force and learning effect. My presumption is that reciprocated meaningful interaction among students acts as a moderator between my intention and learners' interpretation. In 
other words, in such situations, wherein learners have the opportunities to negotiate my intended meaning, those who have not grasped the meaning i have introduced appropriately would ensure their understanding in the course of interaction with their team members.

In addition to the theories explained up to this juncture in my paper, there are specific well-known hypotheses in the field of language teaching/learning that directly support CTBL settings. Among them is my own hypothesis, "Multiple Input-Output Hypothesis", one of the axe' of my approach. The remainder of this paper is a brief discussion on the relations of some of these hypotheses with CTBL situations.

\subsection{The input hypothesis}

According to Krashen (1985), learners acquire a language as they get meaning in that language via the input the environment affords them. Hence, the input should be enough and comprehensible. At the same time, he continued, it should be slightly higher $(+1)$ than the present knowledge (i) of learners. This kind of input (the input at ' $i+1$ ' level), whether in written or spoken language, facilitates the advancement of language competence of learners. It is widely recognized that such input is one of the main prerequisites for the acquisition of language. Almost all theories and approaches to SLA in one way or another appreciate the significant role of input in language learning. For example, while proponents of UG consider input as 'food for an inner linguistic system', others like Ellis (2002) have appreciated it for bringing and enhancing frequency of language use among learners.

Before trying to link my instructional approach to The Input Hypothesis, it is worthy of note that Krashen's concept of $i+1$ has nothing in relation to Vygotsky's metaphor of ZPD. They, as Lantolf and Thorne (2006) also put it, are unrelated in three areas:

1) in their conceptualisation: A passive body listening versus collaborative activity;

2) in their philosophical underpinnings: Learner as autonomous versus personal ability co-constructed through activity with other people and artifacts in the environment, and

3) in their focus processes: Child-like learning versus the collaborative accomplishment of a specific task. (p. 273)

It is thereby important to bear in mind that the input hypothesis is not directly appreciative of interaction with others in social contexts, as it is in CTBL settings. Krashen, influenced by the concept of LAD of Chomsky, was under the impression that the process of acquisition of language is driven by LAD rather than by interaction with others. CTBL, however, appreciates the significance of input in learning by focusing on providing sufficient input for more effective learning. I have tried to bring the required input through harnessing some specific activities and class settings and structures. The mechanisms CTBL applies (e.g., through its evaluation systems) bring multilateral interaction and active participation of learners in different stages in the course of negotiation for meaning, in which they have the opportunity to structure their own discourse. Needless to say, in such input-rich contexts, the nature of input is tuned to students' styles, and so ensures its comprehensibility. One may, however, argue that, in such situations, students are also exposed to incorrect forms of L2. But, as Zhang (2010, p.82) also confirms, "there is a principle that interaction drives learners to produce more accurate and appropriate language". Further, Krashen and Terrell (1983) have also commented on this issue: "Our experience is that interlanguage [intermediate forms of the L2] does a great deal more good than harm, as long as it is not the only input the students are exposed to. It is comprehensible, it is communicative, and in many cases, for many students it contains examples of $\mathrm{i}+1$ " (p. 97).

\subsection{The output hypothesis}

Some scholars have taken the stand that input is essential but not enough for adequate development of SLA. Swain (1993), who proposed this hypothesis in 1985, averred:

Just speaking or writing is not enough. Learners need to be pushed to make use of their resources; they need to have their linguistic abilities stretched to the fullest; they need to reflect on their output and consider ways of modifying it to enhance comprehensibility, appropriateness, and accuracy. (p. 5)

Therefore, according to Output Hypothesis, even using the language, though favourable to fluency, does not guarantee accuracy and language proficiency. That is, for achieving higher and deeper levels of comprehension and in order to augment the language proficiency of learners, the stress should be both on comprehensible input and on comprehensible output. From the viewpoint of this theory, therefore, 'output' is also a key means for the development of L2 knowledge. 'Focus on form' has been emphasised in this hypothesis for knowledge construction through input and output processing.

Major principles of CTBL are designed for and focused on creating meaningful interaction among students, in 
genuine environments, in order to give rise to more productive learning conditions for all students. In a CTBL class, students divided into ten teams, for example, can get ten times as many opportunities to talk as in traditional classes. Such learning contexts provide all students further motivating opportunities to generate greater quantity of language or more negotiated output, in the course of negotiation of their ideas. Besides, due to the immediate feedback learners receive on the comprehensibility of their output from their peers, they are motivated and feel a need to concentrate on form so as to, if necessary, reshape their inter-language resources. This modification process, in turn, as Long and Porter (1985) have also asserted, results in the development of their production skills, in addition to the betterment of their accuracy.

\subsection{Noticing hypothesis}

Schmidt (2001) in his Noticing Hypothesis has considered intake as that part of the input that the learner notices. He has opined, "SLA is largely driven by what learners pay attention to and notice in target language input" (ibid, p.3). That is, SLA occurs when learners consciously notice interlanguage and target language forms, lexicon, pronunciation, and so on and test their hypotheses about what works and is acceptable in language they use. In so doing, they would be in a position to modify their interlanguage systems in order to negotiate their ideas more precisely.

In order to enable students to acquire the language and of course to generate authentic messages, which is among CTBL goals, $i$ try to practice them not just to pay sufficient attention to new input but concentrate on what they want to generate or even on what they are generating/output. Further, i also spur students into making efforts to ensure that their messages are communicated. It is necessary to note that one of the major reasons for my emphasis on the important role of interaction in learning situations refers to my assumption that interaction could also serve learning environments as an attention-driven device, to use a term from Robinson (1995). In my method, thus, i have focused on interaction in order to appreciate the significance of attention in mediating between input and learning. In an attempt to provide hints as to how interaction contributes to L2/FL acquisition, Gass (1997) has referred to interaction as a 'reinforcing device'. He has elucidated that interaction subjects participants to negative feedback, thereby drawing their attention to language form in a meaning-oriented context and making them produce more accurate and complex language.

\subsection{Affective filter hypothesis}

In his Affective Filter Hypothesis, Krashen (1985) has argued that in spite of the important role of exposure of learners to comprehensible input for the promotion of their SLA, it is not enough. Openness of the learner to input is also a must for the acquisition of language to occur. Krashen continued that this openness depends on the learner's level of affective filter. He defined affective filter, as a screen of feelings such as anxiety, motivation, attitudes, and self-confidence that can deter or barricade language acquisition or learning if it keeps the learner, from getting engaged in communicative exchanges and the learning process. Therefore, even a feeling of over confident, for example, can also act as a block to learning if it de-motivates the learner to take an active role in class activities. According to Krashen, when the affective filter is low (i.e., the learner has high motivation, normal self-confidence, a good self-image, a low level of anxiety, etc.) the probability that input becomes intake increases.

I am strongly in agreement with the idea that success in learning depends not just on cognitive aspects, but on affective aspects of learning (e.g., students' attitude and the psychological environment in which instruction takes place). Regarding Krashen's hypothesis, i am even of the view that noticing may also encounter problems if affective filter is high. Therefore, as it is realised, CTBL appreciates an atmosphere that aims at lowering the affective filters of students. Such highly psychologically safe, relaxing, and less anxiety-producing environments give rise to learners' enthusiasim to pay attention to the input in order to understand it, and proactively use the language thereby increasing the quality of their learning. Stern's (1992) has also appreciated such learning contexts by asserting that if the language class is meant to be a place where individuals can practice in communication in the foreign language, it is vital to establish a social and affective climate in which students are not restricted, aggressive, or feared.

\subsection{Interaction hypothesis}

Long (1996) in his Interaction Hypothesis, which was first posed in 1981, has considered interaction as a vital requirement for effective language learning. He has maintained that in the course of interaction or negotiation for meaning, learners come across some communication problems and have the opportunities to negotiate the solutions to the problems by requesting for repetition, explanation, clarification, and paraphrasing for confirmation or comprehension checks. Such activities in such situations, he has conceded, add to the quantity of comprehensible input, which can result in modified output. He has suggested, "negotiation for meaning ... 
facilitates acquisition because it connects input, internal learner capabilities, particularly selective attention, and output in productive ways" (ibid. pp. 451-452). Interaction, from the viewpoint of this hypothesis, brings with it clarity in message which in turn smoothes and fosters the development of language learning.

Before trying to link CTBL to the Interaction Hypothesis, i would like to digress a moment to make a brief but important and to-the-point distinction between Vygotskian view of learning and that of Interaction Hypothesis availing myself of ideas of scholars like Ellis' (2003) in this regard: Vygotsky and his associates view learning as the result of 'taking part' (participation) in social activities, which have the potential to mediate learning, in lieu of 'taking in' (acquisition) of merely linguistic input, as it is suggested by Interaction Hypothesis. The Interaction Hypothesis views 'interaction' merely as 'the means by which input is made available to the black box. It likewise considers interaction as an opportunity for producing 'output'. It would also be well worth noting in this juncture that the Output Hypothesis considers 'output' merely as the means for the development of L2 knowledge 'inside the black box'.

As elaborated, in CTBL, the presupposition is that socio-economic environment has a significant influence on the linguistic and cognitive development of individuals. The belief is that context gives meaning to content, and that language is context specific; that is, what is learnt about language is a reflection of interaction with others within learning situations. In other words, language use and language learning are interactive activities which occur best in contexts that encourage negotiation of meaning. Further, as noted, i appreciate the role of interaction as an attention-driven as well as reinforcing device also. These are part of the reasons as to why the provision of an effective, supportive, relaxing, communicative, referential, and developmentally motivating and appropriate learning-for-all learning and social atmosphere in the classroom is the main area of concern of CTBL.

\subsection{Multiple Input-Output Hypothesis}

As it was explained, according to Noticing Hypothesis, only that part of the (comprehensible) input which is noticed could find a mental home and so become intake. Let me continue that this may best happen if the environment is relaxing and affective filter is low, and if interaction and output are encouraged. The point however is that intake is not sufficient: Students need to communicate their understandings. And the problem is that, as a number of researchers like Jiang (2010) have also confirmed, not all the intake could be transformed into productive skills (i.e., writing and speaking), albeit they more easily contribute to listening and reading abilities of students. Worse yet, to my best knowledge, there is no didactic theory or hypothesis that proposes an effective solution for contribution to this kind of transformation. This thought-provoking gap in the present related literature inspired me to propose my hypothesis, "Multiple Input-Output Hypothesis", as under, in order to address the dilemma, and in so doing contribute to the success of ELT:

Though input, low affective filter, noticing, output, and even interaction (even as it is considered by constructivists) are crucial, they are not sufficient conditions for more effective and comprehensive SLA to take place in language classes: Greater and more systematic focus should be on the transformation of the intake into productive skills. And the provision of 'multiple sources' of both 'input' and 'output' in learning environments is an appropriate solution for more effective contribution to this kind of transformation.

Realising the importance of multiple sources of input and output in language acquisition, i proposed the Multiple Input-Output Hypothesis to serve my instructional approach as an axis. I have tried to bring multiple sources of input and output through the implementation of different activities and strategies in bona fide and highly structured motivational- as well as dialogic-based CTBL relaxing interactive environments. Encouraging peer discussion in different stages, appreciating the significance of multiple whos, and valuing 'language' 'as a whole' (i.e., integrating all facets of language, which as Arslan (2008) also asserted is not appreciated in the arena of ELT today) are among them. To cite an example, i appreciate all (sub-) skills of language even in specific courses, run through CTBL, to facilitate the mentioned transformation. In my reading courses, for instance, in addition to listening, speaking and writing are also considered as complementary skills to reading. The belief is that whole language, rather than its isolated parts, carries more meaning, which should be negotiated and processed in my classes. Furthermore, these skills have many characteristics in common, and so their effects are interwoven. Also, the fact is that in order to prove their academic reading abilities, especially at the collegiate level, students need to communicate properly. These are parts of the reasons for accommodating writing activities like note taking, outlining, paraphrasing, and summarizing in learning environments that highly encourage 'oral' negotiation of themes and ideas as complementary activities to reading in my reading classes. These activities in such situations are conducive to further involvement of students in collaborative learning and encourage them to focus and concentrate not just on semantic but also on syntactic components of texts at hand 
which make learning more purposeful. It goes without saying that this kind of context seeks mutual input-output treatment and also deeper analysis of both input and output not just for meaning but for accuracy and frequency as well and so solicits deeper levels of cognition. And all these, in their turn, contribute to students' in-depth 'comprehension' of the material and also to their productive skills. These in-my-classes social activities (reading, listening, speaking, and writing), thereby, not only serve my classes as multiple sources of input and output, they also contribute to further sources of input and output. The nature of the interactive learning situation occasioned by the appreciation of these four skills, for example, plays its role as a mediator between 'input' and 'output'. In sum, all these mechanisms assist to turn 'input' into 'understanding' and 'understanding' into 'output'; that is, they contribute to the transformation. Such communicative situations also facilitate students to develop all aspects of their communicative competence as they, for example, provide them the opportunities to learn not only about the language but also about how to use the language appropriately in semi/authentic environments. Moreover, such contexts are also more likely to bolster students' different aspects of 'thinking' abilities, in implicit and explicit ways (see also Holliway, 2009), which in their turn contribute to productive skills, long-term retention of information, which is a criterion for real learning, and successful living. It is essential to note that the idea of integrating all skills of language is consistent with the ideas of specialists like Nunan (2005, cited in Arslan, 2008, p. 3) who deem "skills integration as an important feature of language learning, appealing to such notions as interaction, task continuity, real world focus, language and learning focus and task outcomes".

Apart from the theories and hypotheses discussed thus far, there are likewise a considerable number of theories which appreciate the potential positive impacts of CTBL environments on students' attitudes, abilities, and behaviours. Among such theories are Socio-Linguistic Theory, Sociological Theory, and Engagement Theory.

\subsection{Socio-linguistic theory}

Socio-Linguistic Theory, as in the words of Bernstein (1970), states that getting familiar with different speech patterns is essential for students' future career and life success. And CTBL provides students with potentially different socio-cultural backgrounds with contexts in which they have the opportunities to learn and experience different and a variety of speech patterns. They will internalise the divergent ways different people with variety backgrounds expect them to talk in diverse situations.

\subsection{Sociological theory and social learning theory}

Also, according to Sociological Theory, developed by Allen (1976), individuals tend to be what they are expected and demanded to be by the community they are a member of, its norms, and its culture. And Bandura's (1971) Social Learning theory stresses the importance of modeling on individuals' development. Bandura's theory also focuses on human behaviors in relation to continuous interaction between behavioral, cognitive, and environmental influences. These two theories suggest that under the influence of their surroundings and to fulfil the expectations, individuals - at the initial stages in their academic life -- are bound to change their attitudes and behaviours so as to satisfy themselves and also obtain the approval and acceptance of their groups and communities. In CTBL settings, thus, teachers are endowed with the opportunities to practice students in humanitarian approaches to thinking and living and fine-tune their attitudes towards classmates, curriculum, and the real world and thereby change their behaviour. They could develop especially sheep-like students in such a way to be desirous of transforming the shepherd and his tribe rather than accepting to be scarified by them for their survival. This could also be enhanced by assigning special roles in intended-made teams for the target students, for instance.

And finally the Engagement Theory of U.S.A. edu-technologists, Karsley and Shneiderm is also in support of CTBL, as it, as Huang (2010, p.460) also confirmed, "emphasizes cooperation, creativity and contribution".

\section{Reflection, conclusion, and closure}

CTBL is one of the few exceptional instructional approaches that is central to and consistent with such diverse but well-known theories and hypotheses. They justify the claim that contrary to the conventional instructional approaches which have already failed to bring their practitioners effective learning, values, and skills for personal and moral development (Hosseini, 2007), the nature and the characteristics underlying this fundamentally different approach to Education/ELT are conducive not only to the enhancement of more effective (language) learning strategies, long-term retention, and academic success. They are also favourable to flexible and active learning, interactive competence, and the acquisition of some crucial habits of mind such as objectivity, and critical and creative thinking which are essential requirements for successful relationship and living in the present world context. As it was also indicated in my studies, and as it is realised from the mechanisms and the principles inherent in it, and also considering its magic transforming power especially for transforming today 'sheep-like reticent bench-bound adaptable-to-the-world recipients/objects' into 'Agents of 
change or the Subjects who have the capacity to influence the world', CTBL is, in nature, an approach to the empowerment and the liberation of the Other or the oppressed/the weak/the poor who have their own identity, attitude, ideology, and so forth but are almost always purposefully ignored, marginalised and deprived from their rights, and in short - insensibly - victimised, by the traditional Imperialists' didactic modes of education like the Banking Method. To put it another way, my instructional innovation is, in point of actual fact, in the last analysis, an inimitable approach to the elimination of apartheid and dictatorship who is in the habit of hegemonic articulation/presentation or infusion of their ideas, attitude, ideology, and so on. My method, to be brief, is a 'catalyst for change': It is a weapon - a sophisticated, strategic, and apt pedagogic weapon for the elimination of barbarous animals from among human societies in the third millennium. As a Muslim thinker, i developed CTBL because the truth is that from the viewpoint of 'real' Islam - as it is in any other religion and humanitarian outlook, God has bestowed democracy upon humanity. According to real Islam, all people have 'the liberty' to 'think', and they have 'the right' to 'decide', 'choose', and "live". I will have more to say about this issue in my next articles and books, if THEY let the remainder of my family and $i$, who are always in a sense of impending doom, survive their horrifying antediluvian approaches to pressurizing and mind torturing. CTBL, in brief, must be appreciated in the sense that it is a value and a to-the-point approach to the attainment of the ultimate goal of contemporary Education, which is the prosperity of the societies the world over, especially in the context of ongoing globalization in the present complicated 'competitive' world.

\section{References}

Allen, V. L. (Ed.). (1976). Children as teachers. London: Academic Press.

Arslan, A. (2008). Implementing a holistic teaching in modern ELT classes: Using technology and integrating four skills. International journal of Human Sciences, 10 (10), 1-21. Online available at: http://ssrn.com/abstract=1259392. Accessed September 2010.

Bandura, A. (1971). Social Learning Theory. NJ: Prentice Hall Regents.

Bandura, A. (1977). Principles of behavioural modification. New York: Holt.

Bernstein, B. (1970). A socio-linguistic approach to socialization. In J. Gumpers \& D. Hymes (Eds.), Directions in sociolinguistics. New York: Holt.

Brookfield, S.B. (1986). Understanding and facilitating adult learning. San Francisco, CA: Jossey-Bass.

Candlin, C. N. \& Widdowson, H. G. (Eds.). (1987). Classroom interaction. Oxford: OUP.

Dewey, J. (1938). Experience and education. Kappa Delta: Pi.

Duffy, T. M. \& Cunningham, D. J. (1996). Constructivism implications for the design and delivery of instruction. In D. H. Janassen (Ed.), Handbook of research for educational communications and technology. New York: Macmillan.

Dunn, W. \& Lantolf, J. P. (1998). Vygotsky's Zone of Proximal Development and Krashen's I+1: Incommensurable Constructs; Incommensurable Theories. Language Learning, 48, 411- 442.

Ellis, N. C. (2002). Frequency effects in language processing. Studies in Second Language Acquisition, 24 , $143-188$.

Ellis, R. (1994). The study of second language acquisition. Oxford: OUP.

Gartner, A., Kohler, M. \& Riessman, F. (1971). Children teach children. Learning by teaching. New York: Harper \& Raw.

Gass, S. (1997). Input, interaction, and second language learner. Mahwah, NJ: Erlbaum.

Holliway, D. (2009). Towards a sense-making pedagogy: Writing activities in an undergraduate learning theories course. International Journal of Teaching and Learning in Higher Education, 20 (3): 447-461.

Hosseini, S. M. H. (2000). The effects of competitive team-based learning on the reading comprehension of high school students. Unpublished MA Dissertation. Garmsar Azad University, Iran.

Hosseini, S. M. H. (2000). The effect of competitive team-based learning on the reading comprehension of Iranian senior high school students. Roshd FLT Journal, 20, 42-49.

Hosseini, S. M. H. (2006). Third (and last) main speaker at International Forum on 'Global Peace and Civic Action'- sponsored by National Federation of University Co-operative Association, Japan, held at Mysore, India on August 11-12, 2006. 
Hosseini, S. M. H. (2007). ELT in Higher Education in Iran and India: A Critical View. Language in India, 7(12). [Online] Available: http://www.languageinindia.com/dec2007/eltinindiaandiran.html, December 15, 2007.

Hosseini, S. M. H. (2009). Infusion of Emerging Online Technologies into ELT: The Need of the Hour", Perspectives in Education, 25, 119-127.

Hosseini, S. M. H. (2010). Cooperative learning methods +1 : Theory, research, innovation, and application -Forthcoming.

Jacobs, G. M., McCafferty, S. G. \& DaSilva Iddings, C. (2006). Roots of cooperative learning in general education. In S. G. McCafferty, G. M. Jacobs, \& A. C. DaSilva Iddings, (Eds.). Cooperative learning and second language teaching. New York: CUP.

Jiang, Y. (2010). A feasibility study of applying "double-output hypothesis" into task-based teaching approach in second language acquisition. Language Teaching and Research, 1 (4): 397-400.

Kearsley \& BenShneiderman. Engagement Theory: a framework for technology-based teaching and learning. http://home.sprynet.com/ gkearsley/engage.htm (accessed 4/5/1999).

Kessler, C. (Ed.). (1992). Cooperative language learning: A teacher's resource book. Englewood Cliffs, NJ: Prentice-Hall.

Knowles, M.S. (1970) The modern practice of adult education: Andragogy vs. pedagogy. New York: Association Press.

Krashen, S. D. (1985). The input hypothesis: Issues and implications. London: Longmont.

Krashen, S. D. \& Terrell, T. D. (1983). The natural approach. Oxford. Pergamon.

Lantolf, J.P. \& Thorne, S.L. (2006). Sociocultural theory and the genesis of second language development. Oxford. OUP.

Long, M. H. (1996). The role of the linguistic environment in second language acquisition. In W. C. Ritchie \& T. K. Bhatia (Eds.), Hand book of second Language acquisition (pp. 413-468). San Diego, CA: Academic Press.

Long, M. H. \& Porter, P. A. (1985). Groupwork, inter language talk, and second language acquisition. TESOL Quarterly, 19, 207-228.

Newman, F. \& Holtzman, L. (1993). Lev Vygotsky: Revelutionary scientist. New York: Routledge. Tempo.

Ohta, A. S. (2001). Second language acquisition process in the classroom: Learning Japanese. Mahwah, NJ: Erlbaum.

Piaget, J. (1973). To understand is to invent. New York: Grossman

Piaget, J. \& Inhelder, B. (1969). Psychology of the child. New York: Basic Books.

Richards, J. C. \& Rodgers, T. (2001). Approaches and methods in language teaching (2nded.). Cambridge: CUP.

Robinson, P. (1995). Attention, memory, and the noticing hypothesis. Language Learning, 45, 283- 331.

Schmidt, R. (1990). The role of consciousness in second language learning. Applied Linguistics, 11, 129-158.

Schmidt, R. (2001). Attention. In P. Robinson (Ed.), Cognition and second language instruction (pp. 3-32). New York: CUP.

Skinner, B. F. (1968). The technology of teaching. New York: Appleton-Century-Crofts.

Slavin R. E. (2000). Research on cooperative learning and achievement: What we know, what we need to know. In P. K. Smith \& A. D. Pellegrini. (Eds.), Psychology of education: The school curriculum, Vol. 3. (pp. 533-555). London: London \& New York.

Staarman, J. K., Krol, K. \& Van Der Mejiden, H. (2005). Peer interaction in three collaborative learning environments. Journal of Classroom Interaction, 40(1), 29-39.

Stern, H. H. (1992). Issues and Options in Language Teaching. Oxford: OUP. Shanghai: Shanghai Foreign Language Education Press. 1999.

Swain, M. (1993). The output hypothesis: Just speaking and writing aren't enough. The Canadian Modern Language Review, 50, 158-164.

Swing, S. R. \& Peterson, P. L. (1982). The relationship of student ability and small Group interaction to student achievement. American Educational Research Journal, 19, 259-74.

Van Lier, L. S. (1996). Interaction in the language curriculum: Awareness, autonomy and authenticity. London: 
OUP.

Vygotsky, L. S. (1978). Mind in society. Cambridge, MA: Harvard University Press.

Vygotsky, L. S. (1981). The genesis of higher mental functions. In J. V. Wertsch (Ed.), The concept of activity in Soviet psychology. Armonk, NY: M. E. Sharpe.

Webb, N. M. (1985). Student interaction and learning in small groups: A research summary. In R. E. Slavin et al., (Eds.), Learning to cooperate, cooperating to learn (pp. 147-172). New York: Plenum.

Huang, C. (2010). Application of engagement theory in the literary education. Language Teaching and Research, 1 (4), 460-463.

Zhang, Y. (2010). Cooperative language learning and foreign language learning and teaching. Journal of Language Teaching and Research, 1(1), 81-83.

Note. 1. For a comprehensive understanding of CL methods and especially CTBL, see (Hosseini, 2010). -- It is for four years now that $\mathrm{i}$ am looking for a publisher who is willing to publish this book. I solicit your co-operation in this regard.

- Important Caution: Educators who employ my approach in countries ruled by a dictator/fascist will be wiped out -- sooner or later, most probably through insensible but barbarous approaches. 